\title{
A necessidade de identificação como barreira ao acesso à informação: evidências e práticas no Brasil e no mundo
}

The need for identification as a barrier to access to information: evidence and practices in Brazil and the world

La necesidad de identificación como barrera al acceso a la información: evidencias y prácticas en Brasil y en el mundo

Karina Furtado Rodrigues Doutorado em Administração (Concentração em Instituições, Políticas e Governo) pela Escola Brasileira de Administração Pública e de Empresas, da
Fundação Getúlio Vargas Professora Assistente no Instituto Meira Mattos, da Escola de Comando e Estado-Maior do Exército. http://lattes.cnpq.br/6904892974412045 https://orcid.org/0000-0001-9330-6399 karinafrodrigues@gmail.com

Robert Gregory Michener Doutorado em Ciência Política pela Universidade de Austin, Texas Professor Assistente na Escola Brasileira de Administração Pública e de Empresas, da Fundação Getúlio Vargas http://lattes.cnpq.br/2465553753502316 https://orcid.org/0000-0002-6648-8649 gregory.michener@fgv.br

Resumo: As leis de acesso à Informação (LAI) foram criadas para gerar transparência, fornecendo aos cidadãos acesso aos dados oficiais dos governos. A capacidade de obter informações públicas, no entanto, pode ser restringida por funcionários públicos: diversos experimentos mostram que os funcionários públicos discriminam as respostas aos pedidos de informação dos cidadãos com base em suas características, podendo infringir seu direito de saber. Este artigo analisa como as leis internacionais gerenciam as informações de identidade daqueles que enviam solicitações. Portanto, propõe-se uma tipologia de leis de acesso à informação tendo em conta os itens obrigatórios de identificação. Desenvolveu-se essa tipologia examinando as LAI de 111 países e a aplicando aos 18 países latino-americanos que as possuem. Ademais, explorou-se como essas obrigacões variam em decretos e portais on-line, analisando também o panorama legal brasileiro e possíveis soluções para o impasse. Os resultados mostram significativa heterogeneidade nas proteções identitárias no mundo, indicando a necessidade de padronizar os requisitos de identificação e os processos de solicitação.

Palavras-chave: acesso à informação, discriminação, anonimato

\begin{abstract}
Freedom of Information laws (FOls) are designed to improve transparency by granting citizens the access to information held by the government. The ability to attain public information, however, may be restricted by public officials. Several experiments show that public officials discriminate among citizen requests for assistance based on their characteristics, infringing their right-to-know. This article analyzes how international laws manage the information about those making FOI requests and proposes a typology of FOI laws that take into accoun identification obligations. We develop this typology by examining freedom of information laws in 111 countries and apply it to the 18 Latin American countries that have FOls. In particular, we explore how these obligations vary in decrees and websites. Finally, we examine the Brazilian legal panorama and possible solutions to the impasse. The results show significant heterogeneity in identity protections, indicating the need to standardize identification requirements and the processes to send requests.
\end{abstract}

Keywords: access to information, discrimination, anonymity
Resumen: Las leyes de acceso a la información (LAI) se crearon para generar transparencia, proporcionando a los ciudadanos acceso a datos oficiales de los gobiernos. La capacidad de obtener información pública, sin embargo, puede ser restringida por funcionarios públicos: varios experimentos muestran que los funcionarios públicos discriminan las respuestas a solicitudes de asistencia de los ciudadanos en base a sus características, pudiendo infringir su derecho de saber. Este artículo analiza cómo las leyes internacionales cuidan de las informaciones de identidad de aquellos que hacen solicitudes. Se propone una tipología de leyes de acceso a la información teniendo en cuenta los ítems obligatorios de identificación. Se desarrolló esa tipología examinando las LAI de 111 países y la aplicando a los 18 países latinoamericanos que las poseen. Además, se exploró cómo esas obligaciones varían en decretos y portales online, analizando también el panorama legal brasileño y posibles soluciones para el impasse. Los resultados muestran una significativa heterogeneidad en las protecciones identitarias en el mundo, indicando la necesidad de estandarizar los requisitos de identificación y los procesos de solicitudes.

Palabras-clave: acceso a la información, discriminación, anonimato

\section{Introdução}

As leis de liberdade de informação são muito mais do que um símbolo da consolidação democrática dos países. Além de serem uma ferramenta de participação cidadã e de controle externo, também são capazes de gerar modificações benéficas nos próprios processos burocráticos governamentais, reafirmando também a liberdade de expressão (Bertoni, 2011; Gruman, 2012; Mendel, 2008).

No mundo, já existem mais de 110 leis de acesso à informação; em toda a América Latina, somente Cuba, Venezuela e Bolívia não possuem leis do tipo. O Brasil foi o 14ํㅜ país latino-americano a aprovar uma desse modelo (Lei 12.547/11), figurando como a $22^{\text {a }}$ lei mais forte do mundo, de acordo com o ranking de leis RTI-Rating. Além disso, o Brasil assina junto aos Estados Unidos como um dos fundadores da Parceria pelo Governo Aberto (Open Government Partnership - OGP - ), iniciativa internacional para a promoção de acesso às informações públicas, governo eletrônico e dados abertos.

Contudo, maior transparência não resulta, necessariamente, em melhores governança, qualidade de vida e resolução de problemas. De acordo com Dowbor (2003), a irracionalidade e o excesso das informações, bem como a falta de estruturas que as tornem uma ferramenta de mudança social, faz com que os

Correspondência/Correspondence: Karina Furtado Rodrigues. Escola de Comando e Estado-Maior do Exército. Instituto Meira Mattos, Programa de Pós-Graduação em Ciências Militares. Praça Gen. Tibúrcio, 125 - Urca, Rio de Janeiro - RJ, 22290-270. karinafrodrigues@gmail.com 
benefícios da transparência sejam obscurecidos e, quiçá, ressaltem ainda mais a ineficiência da máquina pública.

Em meio à enxurrada de informações desnecessárias e propositalmente noticiadas para tirar o foco de políticas e ações que realmente importam, as leis de acesso à informação também surgem como um garantidor de (i) uma transparência mínima necessária para responsabilizar órgãos do Estado sobre suas ações, e também (ii) mecanismos para se requisitar informações importantes que ainda não estejam públicas (Dowbor, 2003; Mendel, 2008).

A adoção dessas leis, contudo, diz pouco sobre sua real implementação, o que fez surgir na literatura uma série de avaliações de cumprimento da lei pelos órgãos públicos. O panorama que esses estudos trazem a respeito do Brasil não é animador: as capitais brasileiras só responderam a 60\% (108 respostas a 180 pedidos) dos pedidos de informação, sendo que do total, apenas $23 \%$ (42 respostas) das respostas eram precisas. No caso dos Tribunais de Contas, de 128 pedidos de informação enviados, apenas $47 \%$ foram respondidos e $26 \%$ replicados de maneira precisa (Barros \& Rodrigues, 2017; Michener, Moncau, \& Velasco, 2014).

A já comprovada ineficiência dos governos em responder ao cidadão pode, no entanto, esconder outros problemas, como a discriminação, recriminação e até mesmo a intimidação e violência por parte da administração pública, muito mais provável quando o indivíduo é identificável pela administração pública.

A identificação de quem pede a informação pode ser muito útil para o exercício do próprio direito, já que possibilita a personalização da resposta de acordo com as necessidades de quem a pede (Mendel, 2008). Contudo, não é difícil imaginar que potenciais solicitantes podem sentir-se intimidados ao fazer essa requisição caso saibam que seu nome, documento de identidade, dentre outras informações pessoais, estarão disponíveis para os órgãos públicos questionados. Essa premissa pode ter ainda maior influência se considerada no âmbito municipal - no qual a proximidade dos agentes públicos e dos solicitantes é muito maior -; e no âmbito da atividade jornalística - naturalmente vista como ameaça pelos governos (Michener \& Rodrigues 2017).

Este estudo parte da premissa de que a identificação obrigatória pode ser uma fonte de discriminação, afetando a probabilidade tanto de receber ou não uma resposta, quanto ao tempo para obtêla, bem como afetando a qualidade destas. Além disso, por vezes até proteções formais da identidade do solicitante são ignoradas pela administração pública.

Ademais, há pouco sentido em exigir identificação do cidadão nos pedidos de informação se esta somente é liberada quando considerada pública, e tão somente, depois de descartadas as possibilidades de restrição de acesso. Nesse sentido, pode-se comparar direito de informação ao de voto - um direito político que requer apenas um meio anônimo de contato para que o solicitante receba a resposta a seu pedido.

$\mathrm{Na}$ literatura internacional já há exemplos de como a identificação dos solicitantes de informação, via leis de acesso à informação (LAl), pode afetar esse direito (Lagunes, 2009; McDonagh \& Paterson 2010; Roberts, 2006), além de registros de assassinatos a ativistas do direito de informação na Índia (Rajam, 2017). Contudo, ainda não existem estudos comparativos, tampouco artigos que tratem do tema na América Latina e no Brasil, lacunas essas que este estudo pretende explorar.

Para tanto, serão analisadas as 111 leis de acesso à informação vigentes no mundo e computadas no RTI Rating, buscado criar uma tipologia de leis de acesso à informação quanto ao tratamento dado à identidade dos usuários. Foram encontrados quatro grupos de leis: (i) leis que requerem um número de identificação oficial - ao todo 13 leis -; (ii) leis que pedem informações pessoais - 38 leis -; (iii) leis que deixam em aberto os requisitos de identificação - 53 leis -, e; (iv) leis que garantem o anonimato - somente 6 leis

Além disso, o presente estudo aplica a tipologia criada à realidade dos países da América Latina, incluindo análises dos decretos regulatórios (de jure) e a aplicação das leis nas plataformas (de facto) de países da América Latina. Essa análise deve-se ao fato de que, por diversas vezes, regulamentos em um nível inferior ao da LAI impõem obrigações adicionais aos solicitantes. Outras vezes, os portais de recebimento de pedidos também podem ignorar as exigências mínimas estipuladas na letra da lei, requerendo preenchimento indispensável de informações pessoais. Os resultados mostram uma desordem em relação às obrigações de identificação na América Latina, na qual é somente nos portais que realmente sabe-se que tipo de identificação é solicitada, tanto no sentido de assegurar o anonimato - (que é o caso do Panamá), quanto no sentido da identificação obrigatória (como Honduras e República Dominicana).

Buscou-se caracterizar a situação do Brasil diante do panorama internacional, sendo que análise indica barreiras constitucionais para o anonimato, mas mostra que o respaldo à proteção da identidade pode ser encontrado na legislação vigente de proteção de dados pessoais. Além disso, exploram-se possíveis soluções à proibição do anonimato, através da encriptação de dados e da centralização do recebimento de pedidos em um setor especializado.

Por conseguinte, este estudo organiza-se da seguinte maneira, além dessa introdução: a segunda seção explora o que diz a literatura nacional e internacional sobre a discriminação na prestação de serviços ao cidadão, investigando também, o que dizem as diretrizes internacionais de acesso à informação pública sobre identificação. A terceira seção averigua a metodologia utilizada na elaboração da tipologia de leis de acesso à informação. A quarta seção apresenta o enquadramento das leis na tipologia em nível internacional, em nível regional (América Latina) e a realidade legal brasileira. A quinta seção discute possíveis soluções e, por fim, a sexta seção apresenta as considerações finais do estudo.

\section{Leis de acesso à informação, identificação e discriminação}

As leis de acesso à informação (LAl) estão presentes em mais de 110 países e são ferramenta reconhecida contra a cultura do 
sigilo, a favor do controle social ativo. O direito de informação carrega consigo um potencial democratizante muito grande, já que não restringe nem o objeto de controle, nem quem quer controlar.

$\mathrm{Na}$ América Latina, a adoção de leis de acesso à informação teve, em grande parte, suporte na necessidade de melhoria nos gastos públicos, no combate à corrupção e na exposição de abusos do poder público. Nesse âmbito, melhorias na transparência e no combate à corrupção vêm sendo exigidas não só em um contexto político interno dos países, mas também por organismos internacionais como ONU e Banco Mundial (Alves 2011; Lopes 2011; Michener 2010; RTI Rating, 2017).

A aprovação de uma LAI é atraente para o chefe de Estado que a aprova por causa de seu valor simbólico e pela popularidade decorrente. Contudo, na prática a lei pode retardar alguns processos, gerar novos custos de gestão e dificultar a aprovação de outras leis.

Um grande problema trazido por esse fator político é que os governantes podem forçar a aprovação de uma lei fraca para apenas conseguir popularidade advinda da (pretensa) defesa da transparência. São as chamadas "gag laws", ou "window-dressing laws", como cortinas ao invés de janelas no governo. Há evidências de que os efeitos de LAl fracas são piores do que a ausência da lei, uma vez que podem regulamentar sistemas de sigilo antes não existentes (Michener, 2011). É na qualidade destas fragilidades legais que mecanismos de transparência aparentemente eficazes se tornam, na verdade, institucionalizações da opacidade.

A obrigatoriedade de identificar-se para pedir informações públicas é uma dessas fragilidades, que pode ser fonte de discriminação, de ausência, morosidade e variação na qualidade das respostas recebidas, como demonstrado em inúmeros experimentos contendo 'sugestões' identitárias de etnia, gênero e classe social (Lagunes, 2009; McDonagh \& Paterson, 2010; Roberts, 2006; Velasco, 2017). Além disso, pode gerar medo de retaliação ou perseguição pelos solicitantes, especialmente quando o conteúdo dos pedidos de informação se relaciona com anticorrupção, ou quando são realizadas em âmbito local - como evidenciam os inúmeros assassinatos a ativistas indianos pela liberdade de informação (Rajam, 2017).

Se as leis não são suficientes para que exista transparência e imparcialidade, elas são, decerto, necessárias e basilares para conduzir o debate, traçar rotas de ação e nortes para políticas públicas. Estando a transparência na agenda internacional de políticas públicas, por conseguinte, surgem numerosos documentos estabelecendo convenções sobre o direito de informação, sejam relativos aos princípios (Article 19, 1999; Mendel, 2008), ou estabelecendo modelos de leis (ACHPR, 2013). Pouca atenção vem sendo dada a esse tema e, para verificar essa assertiva empiricamente, analisamos os principais tratados internacionais e regionais em acesso à informação sendo dispostos em cinco são os modelos internacionais e regionais para essa legislação:

(i) A Lei Modelo de Acesso à Informação para a África (ACHPR, 2013), que apesar de estabelecer um mecanismo claro de realização de pedidos, não faz referência alguma à identificação dos solicitantes; (ii) A Lei Modelo da União Europeia (European Parliament \& Council, 2001), que não menciona requisitos de identificação;

(iii) A Lei Modelo da Organização dos Estados Americanos (OEA, 2010), destacando-se ao afirmar que nenhuma informação do solicitante deve ser requerida, salvo aqueles casos em que o solicitante quer dados sobre si mesmo (habeas data);

(iv) A Lei Modelo do Conselho da Europa, que em seu artigo 6 fala explicitamente que os solicitantes devem permanecer anônimos, salvo os casos em que seja essencial a identificação para o próprio processo do pedido (Council of Europe, 2009);

(v) A Lei Modelo do Artigo 19, que também não menciona requisitos de identificação (Article 19, 2006).

Princípios de anonimato de solicitantes encontram ressonância também no movimento de Dados Abertos: a não-discriminação é o sexto dos "8 Princípios de Dados Abertos Governamentais" (OpenGovData, 2007), que estipula que as informações devem estar disponíveis para qualquer um, sem necessidade de qualquer cadastro.

A presença da garantia do anonimato nas leis modelo da OEA e do Conselho da Europa e nos Princípios de Dados Abertos reforça a necessidade de refletir-se sobre a questão, além de demonstrar que é sim possível possuir esse tipo de proteção legal ao solicitante. Contudo, a aderência dos países a esses mecanismos de neutralidade de identidade, como será demonstrado nas próximas seções, ainda é incipiente.

Há de levar em conta também alguns aspectos conceituais e cognitivos relativos à discriminação e anonimato. Muitas são as constituições que colocam a imparcialidade como um dos princípios da administração pública. Entende-se que um processo é imparcial quando trata todas as partes de maneira equânime, o que gera a necessidade de imparcialidade também dos mediadores do processo.

Contudo, todos os indivíduos estão sujeitos a diversos vieses cognitivos, o que dificulta a criação de mecanismos institucionais de proteção da identidade isentos de efeitos colaterais, como a suposição de que os indivíduos tentem a se sentir livres para quebrar leis quando podem permanecer anônimos (Leach, 2006). No entanto, de acordo com o experimento de Nogami e Yoshida (2013), fraudes tendem a ocorrer mais quando há algum tipo de benefício material do que moral envolvido (como exemplo, favorecer uma causa social com ligações pessoais em detrimento de outra social), o que excluiria esse risco do acesso às informações públicas via LAI.

Outro desafio cognitivo inerente ao anonimato é o fato de que a ausência de identificação cria um viés de que a credibilidade do solicitante é questionável pelo simples fato de querer-se anônimo. A falta de credibilidade que o anonimato gera, portanto, causaria um comprometimento do próprio pedido ou mensagem. Rains e Scott (2007) exploram os efeitos do anonimato na responsividade de agentes públicos e concluem que: a raiz da resistência ao anonimato está no fato de que a incerteza é desconfortável e desagradável; e que os indivíduos sempre tentarão reduzir incertezas e tentar prever o comportamento daqueles com quem se relacionam. O anonimato impede essa avaliação, por conseguinte, presume-se que pedidos anônimos tenderiam a receber respostas padrão e mais superficiais, como forma de controle de incertezas 
por parte da burocracia. Portanto, o estudo de Rains e Scott (2007) reforça a necessidade de construir soluções processuais e institucionais para a proteção da identidade de solicitantes de informação.

\subsection{Evidências de discriminação na literatura}

Alguns estudiosos do direito à informação já vêm testando quão frequente e como ocorre a discriminação pela identificação do usuário em serviços públicos. Um dos estudos mais antigos foi conduzido em 1973, manipulando diversos aspectos do pedido: identidade ideológica de organizações não-governamentais, dificuldade dos pedidos, nível de ameaça implícito na pergunta, estilo da carta, dentre outros aspectos. As restrições no número de manipulações e amostra pequena (111 pedidos para 26 órgãos) dificultam a avaliação estatística. Apesar disso, os resultados mostraram o mesmo nível de respostas tanto para organizações de esquerda como de direita, com a diferença de que esta recebeu respostas mais 'propagandistas' e aquelas, mais orientadas à informação (Divorski, Gordon \& Heinz, 1973, 262).

Este estudo chama especial atenção em contextos de polaridade política. Como demonstrado no experimento, a probabilidade de receber uma resposta pode não ser afetada pela afiliação política, mas o conteúdo recebido sim. Isso demonstra o risco de incumprimento de um dos princípios basilares da administração pública nas democracias, que é o da imparcialidade, baseado em assumpções políticas e partidárias.

Roberts (2006) analisa o contexto da LAl canadense através de um experimento relacionado às profissões, enviando pedidos identificados como jornalistas, legisladores, grupos ativistas, dentre outros. Descobriu-se que estas três primeiras eram consideradas de tratamento 'sensível', enquanto as outras receberam respostas mais completas.

Outro estudo da Open Society Justice Initiative, apesar de não seguir metodologia rigorosa de experimentos, demonstrou que perfis profissionais diferentes recebem respostas em tempos diferentes também. No relatório Transparency and Silence (Open Society Justice Initiative, 2006) dos 1926 pedidos de informação para 14 países diferentes - 7 com LAl e 7 sem LAI -, 32\% dos pedidos de organizações não-governamentais receberam respostas dentro da média de tempo; $26 \%$ dos pedidos jornalistas, $19 \%$ dos pedidos de empresários e $11 \%$ dos pedidos vindos de minorias (p. 162).

Os experimentos de Roberts (2006) e da Open Society Justice Initiative (2006) demonstram que a identidade profissional pode afetar diretamente a probabilidade de receber uma resposta dos governos. Esses experimentos contaram com a adição dessa informação nos pedidos, mas tratando-se de jornalistas e pesquisadores conhecidos, o mero acesso aos seus nomes verdadeiros já poderia desencadear um tratamento 'diferenciado', o que aumenta a necessidade da criação de políticas de neutralidade da identidade.
E se o tom do texto do pedido de informação influenciasse na resposta? Cuillier (2010) fez esse teste nos Estados Unidos enviando um grupo de pedidos com um tom informal e amigável e outro grupo com um tom ameaçador e técnico. Os resultados mostraram que o tom ameaçador consegue mais respostas do que o tom amigável, sugerindo discriminação pelo nível profissional e técnico demonstrado no pedido. Esse resultado é grave, já que pressupõe que aqueles cidadãos sem capacidade profissional e técnica para escrever pedidos formais e ameaçadores tenderão a não ser respondidos, ou a obter menos informações. Além do mais, o resultado evidencia a cultura burocrática de transparência como favor ou desvio de função, ao invés de transparência como dever democrático.

Há também experimentos com resultados otimistas. Na Índia, Peisakhin (2012) comparou a efetividade de pedidos de informação via LAI versus o oferecimento de propina para se conseguir informações sobre benefícios sociais. Os resultados encontrados mostraram que as taxas de retorno positivo foram muito parecidas entre os dois grupos, demostrando que a LAI praticamente anula os efeitos de discriminação de classe entre respondentes. É importante ressaltar que a lei de acesso indiana protege o anonimato do solicitante, ou seja, as respostas foram dadas independentemente da identidade do solicitante, o que demonstra a grande força da LAI no país.

Adicionalmente dois experimentos testaram os efeitos da origem do nome do solicitante nas respostas da administração pública, ambos com resultados relativamente positivos. Lagunes e Pocasangre (2016) enviaram 14 perguntas para diversos órgãos do governo do México, metade das quais vindas com sobrenome de alguém tipicamente de alta renda, com a outra metade vinda da identidade de uma pessoa com sobrenome popular. No total, os 241 envios demonstraram a imparcialidade da administração pública nas respostas dadas. Contudo, dado que o sistema mexicano centraliza as informações pessoais dos solicitantes, há a possibilidade de a variável de manipulação não ter funcionado corretamente.

Grohs, Adams e Knill (2016), por sua vez, exploram o tema por meio de requisições de informação no principal meio de contato de governos locais na Alemanha, controlando variáveis como origem étnica do sobrenome (sobrenomes turcos versus alemães) e gênero. Os resultados não exibiram evidências de discriminação por origem étnica, só havendo uma pequena diferença na completude das respostas. Os resultados relativos ao gênero só indicaram discriminação entre as identidades com sobrenomes turcos, ao passo que entre sobrenomes alemães não houve diferença.

Nacionalmente foi realizado um experimento na Avaliação de Transparência do Ministério Público (Moncau, Michener, Barros \& Velasco, 2015), comparando a taxa de respostas, taxa de precisão e tempo de respostas entre (1) uma identidade com vínculo com instituição de pesquisa conhecida e (2) uma identidade sem vínculo institucional forte, não encontrável nas redes sociais. A premissa é de que ao terem acesso ao nome e identidade dos solicitantes e, 
porventura buscando informações sobre eles na internet, servidores públicos poderiam discriminar de acordo com o que encontram. Foram 193 envios no total, avaliando 29 órgãos diferentes. Não foram encontradas diferenças substanciais entre os dois grupos de respostas, contudo, o número de respostas precisas foi tão baixo que foi impossível determinar estatisticamente se houve discriminação ou não - de 193 envios, apenas 99 (51\%) foram respondidos, e apenas $53(27 \%)$ tiveram respostas consideradas precisas.

Já em estudo recente, Velasco (2017) conduziu um experimento similar ao do Ministério Público, no qual testou o efeito de vinculação institucional, gênero e nível de sensibilidade do pedido. O experimento contou com o envio de duas questões para diferentes órgãos municipais, totalizando 361 pedidos em que os resultados seguem a tendência de obtenção de poucas respostas: apenas $37 \%$ dos envios foram respondidos. Contudo, diferentemente do experimento anterior, os resultados estatísticos sobre a ocorrência de discriminação foram significantes: as identidades com vinculação institucional tiveram uma taxa de resposta de $46 \%$, enquanto as identidades sem vinculação tiveram taxa de resposta de $31 \%$. Felizmente, a hipótese de discriminação por gênero foi rejeitada (Velasco, 2017).

Isso nos leva a reiterar a proposição de que os riscos de identificação ao direito de informação existem e devem deixar de ser vistos como 'questões' para serem observados como problema de políticas públicas (Souza, 2006). Dessa forma, é englobada a criação de um arcabouço legal que contemple proteções à identidade desde o nível federal até o nível local. Posto isso, as próximas seções tratam do diagnóstico de como o assunto vem sendo tratado pelas legislações internacionais, latino-americanas e brasileiras.

\section{Procedimentos Metodológicos}

Este artigo conta com três análises: uma macro, que inclui os 111 países com leis de acesso à informação presentes no RTI Rating; uma análise meso, que inclui dados sobre a América Latina; e micro, que apresenta a análise da legislação brasileira. O RTI Rating avalia e classifica leis de acesso à informação do mundo todo seguindo os parâmetros da lei modelo da Organização dos Estados Americanos (OEA), e fornece extensa base de dados com legislações, a pontuação de cada um dos indicadores e comentários dos codificadores. O indicador 14 é justamente sobre a necessidade de identificação, foco de análise neste artigo.

O ponto inicial da análise foi a criação de uma tipologia de identificação de solicitantes nas leis em que dois codificadores analisaram a legislação de cada país, atribuindo livremente categorias a cada uma das leis. Após a atribuição livre, os dois codificadores realizaram a consolidação das categorias, que resultou nas seguintes: (i) leis que requerem um número de identificação oficial, (ii) leis que pedem informações pessoais, (iii) leis que deixam em aberto os requisitos de identificação e (iv) leis que garantem o anonimato.
A partir da criação da tipologia, tem-se a análise macro, na qual outros dois codificadores avaliaram novamente o indicador 14 do RTI Rating, agora, atribuindo a cada país uma das categorias previamente definidas. Discordâncias entre os codificadores foram discutidas uma a uma até que se chegasse a um consenso.

A análise meso da América Latina visou aplicar a tipologia não só a leis federais ou nacionais, mas também a decretos regulamentadores e portais on-line onde se fazem os pedidos de informação. A investigação também contou com dois codificadores, que discutiram diferenças pontualmente até o consenso. Para a classificação de países que não possuem portal único de envio de pedidos de informação, a metodologia adotada foi a de avaliar os requisitos de informação nos sites de cinco ministérios diferentes o que fez com que alguns países figurassem em mais de uma categoria da tipologia.

A análise micro consiste na verificação da legislação brasileira sobre acesso aos dados e anonimato frente ao panorama internacional, além da reunião de alguns casos anedóticos identificados a partir de relatórios de avaliação da lei de acesso à informação no Brasil (Barros \& Rodrigues, 2017; Michener et al., 2014).

\section{Acesso e Identificação no mundo, na América Latina e no Brasil}

Através da análise e codificação das 111 leis contidas no ranking de leis de acesso RTI Rating, construiu-se uma tipologia de tratamento da identidade de solicitantes no mundo. Identificou-se quatro grupos distintos de leis, cada um com suas próprias particularidades e fragilidades em relação à identificação, que são:

(i) Leis que requerem um número de identificação oficial: neste caso, as leis estipulam a necessidade de números de documentos oficiais como carteira de identidade. A obrigatoriedade do fornecimento deste tipo de informação implica na impossibilidade de utilizar pseudônimos para fazer o pedido de informação, já que, se usados, poderiam ser caracterizados como falsidade ideológica.

(ii) Leis que pedem informações pessoais: este agrupamento de leis é bastante heterogêneo, com grandes variações no conjunto de informações pedidas. Órgãos podem pedir desde 'nome' e 'forma de contato', até uma lista sem fim de dados que podem comprometer, via coação, o direito de informação.

(iii) Leis que deixam em aberto os requisitos de identificação: este agrupamento não diz nada sobre ou faz menção muito genérica aos requisitos de identificação. Este grupo é problemático por deixar a cargo de diferentes jurisdições e poderes do Estado a decisão de que tipo de identificação pedir, dificultando a mensuração da efetividade do acesso à informação.

(iv) Leis que garantem o anonimato: Nestes casos nenhuma informação pessoal ou documento é requerida obrigatoriamente. A única informação necessária para se realizar um pedido de informação é uma forma de contato como meio de entregar a informação pedida.

Os três primeiros grupos de leis podem enquadrar-se no que se chama de window-dressing laws, ou seja, leis que podem até ser consideradas um avanço de transparência, mas que, na verdade, estabelecem prerrogativas que dificultam o acesso a dados governamentais (Michener, 2011). El Salvador, Nicarágua, México, Sérvia, Albânia, Eslovênia, Libéria, dentre outros países, podem gabar-se de possuírem algumas das leis mais fortes de acesso à informação no mundo; não obstante, não oferecem prerrogativas de 
proteção de identidade a fim de que o exercer do direito seja minado pelo medo de perseguição e discriminação. As leis que garantem o anonimato, por sua vez, apresentam avanços no tratamento do tema, mas nem sempre evitam perseguição.

As próximas seções dedicam-se a aplicar a tipologia e analisar como os países vêm tratando a identificação dos cidadãos que realizam pedidos de informação em nível mundial, regional (América Latina) e nacional (Brasil).

\subsection{Identificação em 111 leis de acesso à informação}

A análise internacional das leis de acesso à informação apresenta um panorama inquietante em relação ao tratamento das identidades de solicitantes de informação: não há padrões, muitas leis consideradas fortes não apresentam quaisquer proteções a estas identidades, muitas determinam a identificação obrigatória através de documentos oficiais de identificação e outras não fazem nenhuma menção à questão, deixando a matéria no limbo dos decretos subnacionais.

É importante salientar que foram encontradas incongruências entre as pontuações atribuídas pelo RTI Rating (Indicador 14) e a tipologia aqui proposta. Alguns países receberam a pontuação máxima de proteção à identidade, mas em suas leis nacionais pediam informações pessoais, deixavam em aberto a questão da identificação. O caso de El Salvador é o mais gritante, já que recebeu o máximo de pontos no RTI Rating e enquadrou-se no grupo das 'leis que requerem um número de identificação oficial'.

As leis que requerem um número de documento oficial para identificação colocam de forma clara que o solicitante deve fornecer um número de documento oficial do país ou número de passaporte para poder realizar um pedido de informação. Nota-se aqui que, como base de avaliação, utilizou-se a lei de acesso à informação mais abrangente, que é a federal ou nacional, deixando de lado análises de decretos e plataformas.

Ao todo, 13 são os países que pedem número de identificação oficial dos solicitantes, presentes no Quadro 1. Tipicamente eles também pedem, junto ao documento oficial, informações como nome, sobrenome e endereço. Contudo, quando o número do documento parece não ser suficiente para identificar por completo o solicitante, países apostam em outros modos de identificação que dificilmente cumprem outro propósito que não intimidar o solicitante. A Mongólia e o Cazaquistão, por exemplo, pedem por assinatura, além da identificação oficial. El Salvador, por sua vez, pede que o documento de identidade seja digitalizado e enviado ao sistema de pedidos de informação.

\section{Quadro 1 - Leis que requerem um número de identificação oficial e posição no RTI Rating}

\begin{tabular}{|c|c|}
\hline País (posição) & País (posição) \\
\hline El Salvador $\left(8^{\mathrm{a}}\right)$ & 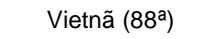 \\
\hline Nicarágua (19aㅗ & Grécia $\left(92^{\mathrm{a}}\right)$ \\
\hline Panamá (33록) & Moçambique (99a) \\
\hline Coréia do Sul $\left(62^{a}\right)$ & Taiwan (103롤 \\
\hline Mongólia (64루) & Cazaquistão (104ª) \\
\hline Malta $\left(68^{\underline{a}}\right)$ & Filipinas (109aㅗ \\
\hline
\end{tabular}

Há vários problemas em exigir-se um número de documento oficial ao solicitar uma informação. Primeiro, ao fornecê-la, o usuário sujeita-se a qualquer tipo de cruzamento de dados que o burocrata responsável tenha acesso, podendo através da identidade inferir, inclusive, a motivação do pedido ${ }^{1}$. Segundo, quando se fornece identificação oficial, fica impossibilitado o uso de pseudônimos para fazer a solicitação de informação, já que, se usados, poderiam ser caracterizados como falsidade ideológica. Percebe-se também que o lugar geral no ranking de força legal das LAl tampouco se converte em proteções à identidade dos solicitantes, já que figuram juntos nesse grupo de leis desde a $8^{\mathrm{a}}$ lei mais forte do mundo (El Salvador) até a lei posicionada em 109 lugar (Filipinas)

Dos tipos de discriminação testados pelos experimentos apresentados na seção 2.1, os solicitantes desses países estão sujeitos a praticamente todos: discriminação por gênero, relação social ou identitária contida em seus nomes, discriminação por afiliação política, dentre outros. Isso porque, de posse do nome verdadeiro do solicitante, pode-se facilmente buscar informações adicionais do usuário na internet ou em outras redes - como demonstrou Velasco (2017) em seu experimento.

Ao todo, 38 leis pedem informações pessoais para identificação. Pedir informações pessoais não é um problema em si - informações de contato são importantes para que se possa responder adequadamente o cidadão. No caso de respostas impossíveis de dar via meios eletrônicos, pode-se utilizar de correspondência em meio físico para se prover informações. A lista destes países pode ser visualizada no Quadro 2.

governo, o que pode resultar em uma não-resposta ou em uma resposta mais superficial.
${ }^{1}$ É o caso, por exemplo, de se identificar um solicitante como jornalista pode-se inferir que a motivação do pedido de um jornalista e investigar
algum assunto sensível que potencialmente pode ferir a imagem do 
Quadro 2 - Leis que pedem informações pessoais e posição no RTI Rating

\begin{tabular}{|c|c|c|}
\hline País (posição) & País (posição) & País (posição) \\
\hline México (1를 & Indonésia $\left(31^{a}\right)$ & Portugal (76루 \\
\hline Sérvia $\left(2^{\underline{a}}\right)$ & Quirguistão (32aㅗ $)$ & $\begin{array}{l}\text { República Tcheca } \\
\qquad\left(78^{a}\right)\end{array}$ \\
\hline Albânia (5aa $)$ & Reino Unido (34룰 & Turquia (79aㅗ \\
\hline Croácia (6ª $)$ & Rússia (35aㅗㄱ & Letônia $\left(80^{\underline{a}}\right)$ \\
\hline Serra Leoa $\left(9^{\underline{a}}\right)$ & Armênia (38aㅗ & China $\left(82^{a}\right)$ \\
\hline Tunísia (11ํaㄹ & Estônia (39aㅗ) & Guiana $\left(86^{\underline{a}}\right)$ \\
\hline Maldivas $\left(13^{a}\right)$ & Chile (43ª) & Eslováquia $\left(87^{\mathfrak{a}}\right)$ \\
\hline Azerbaijão (14ª $)$ & Bulgária (46ª $)$ & Japão $\left(91^{a}\right)$ \\
\hline Macedônia (16 & $\begin{array}{l}\text { Trinidad e Tobago } \\
\qquad\left(50^{\mathrm{a}}\right)\end{array}$ & Lituânia (97ª̣) \\
\hline 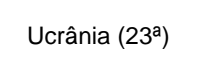 & Montenegro $\left(51^{\underline{a}}\right)$ & $\begin{array}{l}\text { República Dominicana } \\
\left(100^{\underline{a}}\right)\end{array}$ \\
\hline Bangladesh $\left(24^{a}\right)$ & Austrália $\left(58^{\mathrm{a}}\right)$ & Uzbequistão (102ª \\
\hline lêmen (28무 & România $\left(61^{a}\right)$ & Tajiquistão (108ª̂) \\
\hline $\begin{array}{c}\text { Bósnia e } \\
\text { Herzegovina (29aํ) }\end{array}$ & Angola $\left(71^{a}\right)$ & \\
\hline
\end{tabular}

Contudo, essas informações também podem incluir ampla gama de dados pessoais considerada como excessiva no exercício do direito de informação, como endereço residencial (nos casos em que não é necessário o uso dos correios para envio de resposta), endereço de trabalho, gênero, telefone, data de nascimento, dentre outros. O Quirguistão, por exemplo, pede muito mais dados do que os necessários, incluindo nome do pai, data de nascimento e endereço de residência. Outro exemplo é o lêmen, que chega a pedir até o endereço de trabalho do solicitante.

Novamente, percebe-se duas coisas: primeiro, o nome do solicitante, conjugado com outras informações pessoais, pode gerar os mesmos gatilhos para discriminação presentes no grupo de leis que coloca o documento oficial como informação obrigatória; segundo, percebe-se todo espectro de força das leis presente neste grupo - desde a lei mais forte do mundo, que é a Mexicana, até o Tajiquistão, que figura na $108^{a}$ posição do ranking. À vista disso e pelo grande espectro de diferentes combinações de dados pessoais requisitados, esse grupo de leis é um dos mais heterogêneos da tipologia.

No grupo de leis que deixam em aberto os requisitos de identificação, a menção ao tópico foi generalista ou ausente, deixando em aberto para que entidades nacionais e subnacionais estabeleçam seus próprios critérios. Há 53 leis entraram nessa categoria, o que representa $48 \%$ das leis no mundo. Algumas delas citam a obrigatoriedade de "identificação geral", "informações pormenorizadas sobre o solicitante", dentre outros termos genéricos, sem que os itens de identificação sejam determinados a priori. A lista destes países pode ser visualizada no Quadro 3.
Quadro 3 - Leis que deixam em aberto os requisitos de identificação e posição no RTI Rating

\begin{tabular}{|c|c|c|}
\hline País (posição) & País (posição) & País (posição) \\
\hline 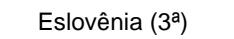 & Argentina (48aㅗ & Equador (75 \\
\hline Libéria $\left(7^{a}\right)$ & Canadá (49aㅗ & Espanha $\left(77^{\mathrm{a}}\right)$ \\
\hline Sudão do Sul (12 $)$ & Jamaica $\left(52^{\mathrm{a}}\right)$ & Zimbábue (81ํaㄹ \\
\hline Antígua $\left(15^{\mathrm{a}}\right)$ & Nigéria (53aㅗ $)$ & $\begin{array}{c}\text { San Vicente \& } \\
\text { Granadinas }\left(83^{\underline{a}}\right)\end{array}$ \\
\hline Quênia $\left(17^{\mathrm{a}}\right)$ & Hungria $\left(54^{a}\right)$ & Ilhas Cook (85 \\
\hline Etiópia (18aㅗ & Ruanda (56 $\left.6^{\mathbf{a}}\right)$ & Israel (89aㅗ \\
\hline Moldova $\left(20^{\underline{a}}\right)$ & Estados Unidos $\left(57^{\underline{a}}\right)$ & Paquistão $\left(90^{\underline{a}}\right)$ \\
\hline África do Sul $\left(21^{\mathrm{a}}\right)$ & Belize (59aㅗ & Dinamarca $\left(93^{a}\right)$ \\
\hline Brasil $\left(22^{a}\right)$ & Honduras $\left(60^{\underline{a}}\right)$ & Guiné $\left(94^{a}\right)$ \\
\hline Nepal $\left(27^{\underline{a}}\right)$ & Holanda $\left(63^{\mathrm{a}}\right)$ & França $\left(95^{\mathrm{a}}\right)$ \\
\hline Colômbia (30aa $)$ & Polônia (65aㅗㄱ & Islândia (96aㅗ \\
\hline Geórgia (36록 & Burkina Faso $\left(66^{a}\right)$ & Paraguai $\left(98^{a}\right)$ \\
\hline Uganda $\left(37^{\underline{a}}\right)$ & Noruega $\left(67^{a}\right)$ & Bélgica $\left(101^{a}\right)$ \\
\hline Irlanda $\left(40^{\underline{a}}\right)$ & Suíça $\left(69^{a}\right)$ & Alemanha $\left(105^{\underline{a}}\right)$ \\
\hline 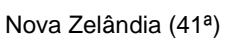 & Afeganistão $\left(70^{\underline{a}}\right)$ & Jordan $\left(106^{a}\right)$ \\
\hline Guatemala $\left(42^{a}\right)$ & Tailândia $\left(72^{a}{ }^{a}\right)$ & Liechtenstein $\left(110^{a}\right)$ \\
\hline Peru $\left(44^{a}\right)$ & $\begin{array}{c}\text { Costa do Marfim } \\
\left(73^{a}\right)\end{array}$ & Áustria $\left(111^{\mathrm{a}}\right)$ \\
\hline Uruguai $\left(47^{a}\right)$ & Níger $\left(74^{a}\right.$ ) & \\
\hline
\end{tabular}

Diferentemente das leis que estabelecem quais informações pessoais serão requisitadas, no grupo de leis que deixa a matéria em aberto acaba-se por delegar os requisitos de informação a entidades subnacionais. Na falta desses padrões, por conseguinte, dificulta-se a padronização do exercício do direito de informação nos países. De tal modo, abre-se uma margem para todo o tipo de abusos nas legislações subnacionais de acesso à informação, bem como nos portais de envio de pedidos - como será evidenciado para a América Latina. Agrava-se essa situação quando situada no âmbito local no qual, devido à proximidade entre cidadãos e entes estatais, a simples obrigatoriedade de fornecer um endereço residencial pode fazer com que muitos cidadãos deixem de enviar pedidos.

No grupo de leis que garantem 0 anonimato dos solicitantes, considerou-se nessa categoria somente as leis que expressam clara e diretamente que o solicitante não precisa fornecer informações pessoais ou sua identidade incluídas. Como mostra o Quadro 4, esse é o menor grupo de países. Seis dos cento e onze países avaliados possuem mecanismos legais que garantem o anonimato dos solicitantes nos pedidos de informação via Lei de Acesso, demonstrando que o debate sobre neutralidade da identidade deve ser expandido. 
Quadro 4 - Leis que garantem o anonimato e posição no RTI Rating

\begin{tabular}{cc}
\hline País (posição) & País (posição) \\
\hline Índia $\left(4^{\mathrm{a}}\right)$ & Finlândia $\left(26^{\mathrm{a}}\right)$ \\
\hline Sri Lanka $\left(10^{\mathrm{a}}\right)$ & Suécia $\left(45^{\mathrm{a}}\right)$ \\
\hline Kosovo $\left(25^{\mathrm{a}}\right)$ & Itália $\left(55^{\mathrm{a}}\right)$ \\
\hline
\end{tabular}

Vale ressaltar novamente a importância das proteções de identidade à luz do caso indiano: mesmo com a proteção à identidade dos solicitantes garantida por lei, dezenas de ativistas do direito de informação reconhecidos publicamente foram assassinados no país (Rajam, 2017). Informação é poder, e uso de quaisquer ferramentas que ajudem em estudos investigativos pode ser alvo de retaliações - a alta taxa de mortes de jornalistas investigativos em países em desenvolvimento também é evidência disso (Marquez, 2017).

É necessário ter em mente as conclusões de Rains e Scott (2007) ao desenhar políticas de proteção à identidade e políticas contra a discriminação e retaliação na esfera pública: o anonimato como proteção também faz emergir a incerteza nos entes públicos, que a tentarão sanar através de algum meio de identificação, seja pelo linguajar da mensagem, seja pelo nome do solicitante, seja buscando informações adicionais em outros meios (Grohs et al., 2016; Lagunes \& Pocasangre, 2016; Roberts, 2006; Velasco, 2017).

Resta saber quão congruentes essas leis nacionais encontramse em relação às outras regulamentações e à própria pratica dos entes públicos. A próxima subseção propõe-se a aprofundar isso.

\subsection{Diferenças entre leis, decretos e plataformas de acesso na América Latina}

Para analisar o panorama de requisitos de identificação nas Leis de Acesso à Informação na América Latina, esta seção apresenta uma análise das diferenças entre leis, decretos e plataformas no que tange à identificação de solicitantes. As classificações das leis pelo RTI Rating são muito úteis para se ter um panorama geral do direito à informação no mundo, mas por serem análises agregadas, não mostram como o direito pode variar entre leis e decretos e nem mostra como a letra da lei se manifesta na prática - ou seja, nos portais de transparência passiva. O Quadro 5 apresenta os resultados da análise.

Os problemas com regulamentações dissonantes das leis de acesso à informação podem ser particularmente comuns em países onde diferentes jurisdições podem criar seus próprios regulamentos.
Quadro 5 - Identificação e Acesso à Informação na América Latina

\begin{tabular}{|c|c|c|c|}
\hline País & Lei Federal & Regulamento & Portal \\
\hline Argentina & ID oficial & ID oficial & ID oficial \\
\hline Brasil & Em aberto & ID oficial & ID oficial \\
\hline Chile & Info. Pessoal & Info. pessoal & Info. Pessoal \\
\hline Colômbia & Em aberto & Em aberto & $\begin{array}{l}\text { ID oficial / } \\
\text { Anonimato }\end{array}$ \\
\hline Rep. Dom. & Info. Pessoal & Info. pessoal & ID oficial \\
\hline Equador & Em aberto & Em aberto & $\begin{array}{l}\text { ID oficial / } \\
\text { Anonimato }\end{array}$ \\
\hline EI Salvador & ID oficial & ID oficial & ID oficial \\
\hline Guatemala & Em aberto & $\mathrm{N} / \mathrm{A}$ & Anonimato \\
\hline Guiana & Info. pessoal & $\mathrm{N} / \mathrm{A}$ & $\begin{array}{l}\text { Info. pessoal / } \\
\text { Em aberto }\end{array}$ \\
\hline Honduras & Em aberto & $\mathrm{N} / \mathrm{A}$ & $\begin{array}{l}\text { ID com } \\
\text { documento } \\
\text { oficial }\end{array}$ \\
\hline México & Info. pessoal & $\mathrm{N} / \mathrm{A}$ & Info. pessoal \\
\hline Nicarágua & $\begin{array}{l}\text { ID com } \\
\text { documento } \\
\text { oficial }\end{array}$ & $\mathrm{N} / \mathrm{A}$ & Variado \\
\hline Panamá & $\begin{array}{c}\text { ID com } \\
\text { documento } \\
\text { oficial }\end{array}$ & $\mathrm{N} / \mathrm{A}$ & Anonimato \\
\hline Paraguai & Em aberto & Info. pessoal & Info. pessoal \\
\hline Peru & Em aberto & ID oficial & ID oficial \\
\hline Uruguai & Em aberto & $\mathrm{N} / \mathrm{A}$ & ID oficial \\
\hline
\end{tabular}

Há outros meandros nas legislações que podem implicar em necessidade de identificação. A Colômbia, por exemplo, estipula em seu decreto possibilidade de responsabilização penal pelo mal-uso de informação; em uma avaliação da LAI realizada no Equador, foi exigida dos solicitantes uma cópia de suas identidades, fotos e até mesmo cobrança de suborno (Centro de Archivos y Acceso a la Información Pública, 2011).

Há também casos positivos, em que ativistas ajudaram na correção de descumprimento da lei, como no caso de Lagos Lira em 2010, que identificou que a polícia nacional do Chile (Carabineros) requeria identidade e assinatura de termo de responsabilidade, requisitos estes que não constam nem na lei, tampouco no decreto de acesso chileno. Com a divulgação da prática tais exigências, foram retiradas da plataforma (Fundación Pro Acceso et al., 2010).

No panorama latino-americano, são poucos os casos em que o que está determinado na Lei de Acesso principal repete-se nos portais e páginas de transparência passiva dos países LatinoAmericanos, seja no lado positivo quanto negativo. Nenhuma das leis de acesso à informação ou suas regulamentações preveem o anonimato ou o uso legal de pseudônimos na América Latina. Contudo, Guatemala e Panamá asseguram o anonimato através de 
uso de pseudônimos em suas plataformas. Na Guatemala, por exemplo, no campo onde se deve preencher com o nome há a menção do pseudônimo como opção. O Panamá é outro caso curioso de aceitação de pseudônimos, já que a lei de acesso do país determina a identificação dos solicitantes por documento oficial. Ademais optou por usar uma plataforma aberta internacional de realização de pedidos, chamada Alavateli.

Em linhas gerais, o panorama de identificação do solicitante no acesso à informação da América Latina pode ser resumido em torno de três pontos:

a) Mudanças de requisitos de identificação entre lei e decreto:

Dos 18 países latino-americanos avaliados, cinco apresentaram mudanças nas exigências de identificação de solicitantes de transparência passiva: Brasil, Colômbia, Equador, El Salvador e Peru. O caso de El Salvador merece destaque, já que o decreto estipula do cidadão que ele digitalize e anexe uma cópia de sua identidade, como um atestado de que se presume a má fé do cidadão. Ironicamente, a Lei de Acesso de El Salvador é considerada pelo RTI Rating como a 9a lei mais forte do mundo , pontuando 122 em um máximo de 150 pontos.

Os casos brasileiro e peruano são similares, já que ambas as leis não definem critérios de identificação, estes que são estipulados em seus decretos cobrando o número de identidade dos solicitantes - o que se reflete fielmente em seus portais de transparência passiva. A Colômbia, por sua vez, deixa implícita a necessidade de identificação no caso de pedidos de documentos que sejam reservados.

b) Mudanças de requisitos de identificação entre decretos e plataformas:

Foram encontradas mudanças entre decretos e plataformas em seis casos: Colômbia, Costa Rica, República Dominicana, Honduras, Paraguai e Uruguai. Cinco desses países (a exceção é o Paraguai) adicionam justamente o requisito de informação que impede o uso de pseudônimos: o número de documento oficial. Reforçando, assim, a necessidade da presença da garantia ao anonimato na lei - quando deixada essa decisão para cada um dos órgãos é impossível saber qual será o entendimento de cada um deles, afetando na uniformidade do exercício do direito de informação.

c) Ausência de plataformas unificadas, gerando heterogeneidade na identificação

Sete dos dezoito países analisados não possuem plataformas unificadas para pedidos de transparência passiva: Argentina, Colômbia, Costa Rica, Guiana, Honduras, Nicarágua e Peru. Para avaliar como os órgãos estão aplicando a lei, foram considerados na amostra cinco ministérios. Os resultados não são animadores, sendo que na maioria das vezes não foi possível estabelecer com clareza uma classificação. Os requisitos de informação foram variados, indo desde informações pessoais demasiadamente detalhadas, passando pela indicação de um e-mail para envio de pedidos (deixando em aberto à identificação), até o pedido de número de documento oficial. Essa também é uma realidade brasileira, quando se considera as diferenças entre esfera municipal, estadual, dos poderes e órgãos autônomos, com exemplos de diferenças nos casos do Ministério Público do Estado do Rio de Janeiro e no Tribunal de Contas do Estado do Rio Grande do Sul, que pedem um número muito grande de informações.

Foi precisamente por causa da heterogeneidade do direito que o México passou de uma lei federal para o que chamam de lei 'nacional'. O novo portal que substitui o InfoMex nasceu dessa reforma criando a Plataforma Nacional de Transparencia, que unifica o envio de pedidos para a esfera federal, estadual e municipal, nos três poderes - evitando, assim, abusos e descumprimentos por parte desses entes (INAI, 2017).

Diante de tal panorama, evidencia-se a dificuldade de avaliar a proteção à identidade dos solicitantes não só na América Latina, mas também mundialmente. A classificação dos 111 países na tipologia consiste em uma análise inicial, posto que não assegura que instâncias locais sejam um espelho das legislações nacionais, como bem exemplificado nesta seção. Não obstante, a identificação desta heterogeneidade consta como primeiro passo para se auferir esta questão que, muito provavelmente, afeta silenciosamente o exercício do direito de informar-se. Tem-se como resultado importante a necessidade de padronizar nacionalmente os meios de realização dos pedidos, solução essa que se encontra não na camada legal, e sim de implementação das políticas.

A seguir, parte-se para a análise legal do Brasil frente à tipologia aqui desenhada, mostrando que os desafios para estabelecer proteções à identidade de solicitantes podem ser ainda maiores, especialmente quando esbarram em questões constitucionais.

\subsection{O contexto brasileiro: barreiras constitucionais}

A Lei de Acesso à Informação (LAI) do Brasil foi aprovada em 2011 após longo debate, e é considerada a 22 $2^{\text {a }}$ lei mais forte do mundo. A LAI brasileira (12.527/11) regula o artigo $5^{\circ}$ da Constituição Federal, em seu inciso XXXIII, provendo suporte legal ao processo de pedidos de informação, a instâncias recursais e à transparência ativa. Anterior à ela, o Brasil contava apenas com a Lei de Arquivos e uma série de decretos que estabeleciam o sigilo irrestrito a documentos classificados (Hott, 2005; Rodrigues, 2017).

O país vem gradual e constantemente se comprometendo com diversos mecanismos de transparência e accountability, no caminho de fortalecimento da democracia pós 1985, e a aprovação da LAI vem inaugurar definitivamente uma cultura de disseminação de dados e prestação de contas na administração pública brasileira (Abdala \& Torres, 2016; Schommer, Dahmer, \& Spaniol, 2014).

Apesar dos avanços, é salutar ter em mente que a aprovação dessas leis não define a qualidade dos dados disseminados (quando disseminados), tampouco dos processos de pedido de informação (Gruman, 2012). As avaliações de cumprimento da LAI 
no Brasil mostram baixas taxas de retorno, bem como qualidade reduzida das respostas a pedidos de informação (Michener et al., 2014; Moncau et al., 2015); as avaliações dos dados disponibilizados nos portais de transparência também deixam a desejar (Barros \& Rodrigues, 2017; Cruz, Ferreira, Silva, \& Macedo, 2012).

Contudo, a LAI brasileira é também uma das leis que figuram, na tipologia, aqui apresentada, entre os países que exigem um documento oficial de identificação como condição para se realizar um pedido, formalizado no Decreto 7.724 (2012) do Executivo Federal, e praticado pela maioria das instâncias do Estado. A obrigatoriedade de identificação não é desprovida de embasamento: o texto da constituição de 1988 (artigo 5º, parágrafo IV) é contundente ao estipular que "é livre a manifestação do pensamento, sendo vedado o anonimato". Mas até onde a vedação irrestrita ao anonimato presente na Constituição pode estar impondo barreiras ao exercício do direito de liberdade de informação no Brasil?

Diversos são os relatos de perseguição política baseada em pedidos de informação considerados ameaçadores para os governos. No Rio de Janeiro, moradores da baixada fluminense recusaram-se a cooperar com ONGs locais na realização de pedidos de informação, com medo de retaliação; e até países que asseguram o anonimato, como a Índia, também sofrem com constantes ataques aos ativistas do direito de informação (Michener \& Rodrigues, 2015).

É importante ressaltar que a rastreabilidade da identidade de um cidadão é fundamental na manutenção da justiça: se não há como identificar de quem infringiu uma lei, é impossível responsabilizar o violador. Contudo, não é só o medo de retaliação que é posto em jogo quando da vedação do anonimato, e a literatura já vem explorando o anonimato como fonte de fortalecimento de direitos humanos e de liberdade de expressão (Martin \& Fargo, 2015; Schulz \& Hoboken, 2016).

Apesar do contexto proibitivo em torno do anonimato e do uso de pseudônimos, deixar o cidadão desprotegido também gera atritos legais em relação a dois pontos: a inviabilização da solicitação e a proteção de dados pessoais.

\section{a) Exigências que inviabilizam a solicitação:}

O artigo 10, parágrafo 1ำ da Lei de Acesso à Informação (12.527/11) é claro ao determinar que "para o acesso a informações de interesse público, a identificação do requerente não pode conter exigências que inviabilizem a solicitação". Esse artigo da LAI brasileira não vem sendo respeitado pelos órgãos públicos, sendo que a lista de itens necessários para identificação muitas vezes inclui um grau de detalhamento demasiadamente pormenorizado do solicitante. Um exemplo é o Ministério Público do Estado do Rio de Janeiro, que exige, além do $C P F, R G$, data de emissão do $R G$, órgão emissor, data de nascimento, e-mail, endereço completo, e telefone - tudo isso por meio de campos de preenchimento obrigatório. Caso ainda mais admirável ocorre no Tribunal de
Contas do Estado do Rio Grande do Sul, que pede que o solicitante digitalize seu documento de identidade para poder enviar o pedido.

As diferenças nos requisitos de informação são, de maneira geral, resultado de regulamentações dissonantes com a lei federal. Os abusos podem ser particularmente mais comuns em países em que diferentes jurisdições podem criar seus próprios regulamentos. Esse problema é bem conhecido no Brasil e um caso que desponta negativamente é o do estado do Rio de Janeiro: o decreto regulamentador da Lei de Acesso estipula diversos elementos ilegais incluindo a assinatura de um 'Termo de Responsabilidade pelo uso e divulgação de informações', contido no Anexo II do documento. Além disso, estabelece que tanto o Anexo I com o pedido, quanto o anexo II como termo de responsabilidade, sejam assinados e entregues pessoalmente em meio físico no órgão a que se destina (Art. 8 do decreto 43.597/2012). Felizmente, apesar das ilegalidades do decreto, foi lançado em 2016 o e-SIC.RJ, que segue os padrões estipulados pela lei $12.527 / 11$, em um portal com formato bastante similar ao e-SIC do governo federal.

\section{b) Proteção de dados pessoais:}

A proteção de dados pessoais também entra em jogo quando a identificação é obrigatória, proteção essa considerada como um direito fundamental por diversos ordenamentos jurídicos (Doneda 2011). Como informações pessoais, consideramos toda a informação que

pode possuir um vínculo objetivo com uma pessoa, revelando algo sobre ela. Este vínculo significa que a informação se refere às características ou ações desta pessoa, que podem ser atribuídas a ela em conformidade à lei, como no caso do nome civil ou do domicílio, ou então que são informações provenientes de seus atos, como os dados referentes ao seu consumo, informações referentes às suas manifestações, como sobre opiniões que manifesta e tantas outras (Doneda, 2011, 93).

O artigo 31 , parágrafo $1^{\circ}$ inciso I da LAl brasileira é claro ao afirmar que "o tratamento das informações pessoais deve ser feito de forma transparente e com respeito à intimidade, vida privada, honra e imagem das pessoas, bem como às liberdades e garantias individuais", sendo que essas informações pessoais "terão seu acesso restrito a agentes públicos legalmente autorizados e às pessoas a que elas se referirem, independentemente de classificação de sigilo e pelo prazo máximo de 100 (cem) anos a contar da sua data de produção".

Se o Estado não dá garantias de que trata com seriedade a segurança das informações pessoais de identificação contidas nos pedidos de informação, coloca-se em xeque o direito de fazer da identificação oficial obrigatória. Urgente é a necessidade de uma resposta para possibilidade de má utilização de dados pessoas por agentes do governo, com a construção de mecanismos de proteção.

Outros países já colocam em prática soluções para a questão. A plataforma de pedidos do México, por exemplo, agrega as identidades dos solicitantes num sistema centralizado que envia pedidos para todos os poderes e níveis de governo, preservando as identidades a um número restrito de operadores (INAI, 2017). Há não obstante, formas de burlar esses sistemas e, ainda assim, 
saber a identidade de quem está pedindo informações, e nisso, a tecnologia pode ser uma grande aliada por meio da encriptação de dados. Na próxima seção exploraremos uma solução emergente para este tipo de problema.

\section{Discutindo soluções: tecnologia e padronização}

A tecnologia pode prover soluções para os empasses relacionados à necessidade de identificação e a liberdade de informação através da encriptação de dados, sobre a qual já há crescente interesse na literatura. A encriptação da identidade de usuários pode proteger e fortalecer direitos humanos, como mostra relatório da UNESCO (Schulz \& Hoboken, 2016), levando em consideração os diversos governos e atores privados que recolhem inadvertidamente informações pessoais de usuários da internet.

Por meio de identidades 'encriptadas' ou 'pseudonimizadas', é possível manter a possibilidade de responsabilização, tratado de forma devida os dados pessoais, sem prejuízo ao direito de informar-se, principalmente num contexto social-político em que o pleno e seguro exercício da democracia vem sofrendo constantes ataques.

É importante ressaltar que alguns tipos de encriptação impedem qualquer rastreabilidade externa dos dados, como é o caso da encriptação ponta-a-ponta - utilizada em aplicativos como o WhatsApp (G1, 2016) -, e alvo de grande polêmica quando sofreu bloqueio. Há de discutir-se, dentro das políticas de encriptação de cada país, os modelos mais factíveis de encriptação e gestão das identidades.

Consequentemente a encriptação de identidades no caso da Lei de Acesso à Informação (LAI) possui mais chances de funcionar com um órgão autônomo com competência para estabelecer diretrizes a todos os entes federativos e poderes - União, Estados, Municípios, Judiciário e Legislativo - que é o que fez a já mencionada Plataforma Nacional de Transparência do México. A centralização faz-se necessária por não ser de muita valia identidades encriptadas em um contexto local, em que a proximidade entre cidadão e possuidor da chave de desencriptação pode ser prejudicial à proteção dos dados.

Além da centralização, ao aplicar o princípio de proteção aos dados pessoais à Lei de Acesso à Informação, o acesso aos dados de um solicitante só seria possível através de um mandado judicial, assim como ocorre com dados bancários e fiscais.

Através de encriptação, centralização dos pedidos de informação em uma única plataforma e a aplicação rigorosa da proteção de dados pessoais, é possível resolver a questão da responsabilização contida na vedação ao anonimato e, ao mesmo tempo, assegurar o direito de informação.

\section{Considerações Finais}

A implementação de uma cultura de transparência não surge apenas com a aprovação de uma lei ou decreto. Ativistas no tema estão passando de uma discussão macro de direitos para abordar questões práticas da implementação das leis, e este estudo inserese nessa última linha. Os fundamentos básicos do acesso à informação são o foco deste trabalho, ou seja, questões procedimentais de transparência passiva que influenciam no cumprimento do direito à informação.

Por um lado, o anonimato dos solicitantes não é ausente de possíveis efeitos negativos nas políticas de transparência, já que pode ser canal tanto de denúncias como de injúria, se desviado de sua finalidade principal, que é o acesso à informação pública. Além disso, há de considerar-se a predisposição dos burocratas a achar suspeitas requisições feitas por pessoas que não querem identificar-se (Rains \& Scott, 2007). Por outro, essa mesma identificação tem gerado diversos tipos de discriminação por parte dos órgãos respondentes, prejudicando o exercício do direito à informação, e até mesmo perseguição e assassinatos (Divorski et al., 1973; Lagunes \& Pocasangre, 2016; Michener \& Rodrigues, 2015; Open Society Justice Initiative, 2006; Peisakhin, 2012; Rajam, 2017; Roberts, 2006; Velasco, 2017).

Diante disso, o presente trabalho propôs a oferecer um panorama de como as leis de acesso à informação (LAI) mundiais, bem como a América Latina e o Brasil, vêm tratando a questão da identificação do solicitante. A realidade mostra que o debate sobre identificação é incipiente, apesar de já ter sido considerado na lei modelo da OCDE. Essa lei modelo serve, inclusive, de base para o banco de dados do principal ranking de leis de acesso à informação do mundo, o RTI Rating. Através da análise desse quesito - o indicador no 14 - para 111 países com leis de acesso à informação, foi possível identificar quatro padrões de identificação: leis que requerem um número de documento oficial; leis que pedem informações pessoais; leis que deixam em aberto os requisitos de identificação; e leis que garantem o anonimato.

A maioria dos países situa-se em zonas ambíguas, como a de informações pessoais (34\%) e a ausência de requisitos (48\%). O excesso de informações pessoais pode levar ao medo de retaliação, sendo comum a obrigatoriedade de fornecer informações como endereço residencial, endereço do trabalho, dentre outros. A ausência de requisitos traz outro tipo de problema: como cada ente governamental pode estabelecer requisitos diferentes, a falta de padronização e controle pode legitimar abusos. $12 \%$ das leis de acesso mundiais estabelecem como obrigatória a identificação através de um documento oficial. Aqui, o espaço para que o cidadão surpreenda-se positivamente com algum órgão governamental é menor, já que isso implicaria em descumprimento da lei nacional. Por fim, apenas $5 \%$ das leis de acesso mundiais garantem a neutralidade da identidade, seja através do anonimato ou de pseudônimos.

Os resultados desta análise mostram que as obrigações de identificação variam independentemente da força da lei. Evidenciase, assim, que a identificação ainda não emergiu claramente na agenda como impeditiva ou dificultadora do acesso às informações, até mesmo em países desenvolvidos. Ao deixar em aberto ou exigir determinados dados, viabiliza-se uma série de discriminações por gênero, origem do nome e profissão, que podem deteriorar o acesso às informações públicas de facto. 
A análise da América Latina apresenta um panorama ainda mais desordenado. Para investigar os efeitos da dissonância entre legislações e a prática, averiguou-se os requisitos de identificação para além da lei nacional, incluindo análises sobre decretos regulatórios e portais de pedidos de informação. Os achados de pesquisa mostram que apenas Chile e El Salvador mantiveram-se na mesma categoria de identificação. O Panamá é um caso curioso, já que em sua lei nacional estipula identificação com documento oficial, mas, na prática, garante o anonimato dos solicitantes. Ademais 10 de 16 países latino americanos com leis de acesso possuem plataformas unificadas para pedidos ao menos na esfera federal. Em 4 dos 6 casos em que não havia plataforma unificada, houve grande variação de informações sendo requeridas.

Esse panorama demonstra a dificuldade de traçar parâmetros legais internacionais para a proteção de identidades, já que mesmo quando leis federais estipulam um padrão de identificação, entes subnacionais e decretos ainda podem ter discricionariedades distintas para acrescentar itens. Contudo, a existência de plataformas unificadas pode ser um importante primeiro passo em busca de, ao menos, padronização. Exemplo disso foi a unificação de plataformas pelo governo Mexicano, cuja Plataforma Nacional de Transparencia centraliza os pedidos enviados a todos os poderes e entes subnacionais do país (INAI, 2017).

O Brasil, por sua vez, figura entre os países que fazem menção genérica aos requisitos de identificação, mas no decreto regulamentador da LAI no Executivo federal estipula a identificação com documento oficial. No entanto, a legislação brasileira oferece uma barreira adicional a políticas de proteção da identidade do solicitante: pela Constituição, é vedado o anonimato. A vedação ao anonimato tem o papel de garantir a possibilidade de responsabilização em caso de descumprimento da lei.

Diversas soluções paliativas podem ser construídas. O portal de acesso à informação brasileiro, por exemplo, poderia garantir o anonimato no processo de encaminhamento aos órgãos requeridos, mantendo a identidade do solicitante restrita solucionaria em parte o problema ${ }^{2}$. Outra opção de reforma seria deixar de exigir documentos oficiais dos cidadãos, permitindo que eles utilizassem pseudônimos no envio de pedidos de informação. Entra na pauta também a criação de plataforma unificada de pedidos de informação incluindo estados, municípios, demais poderes e órgãos autônomos, novamente a exemplo da Plataforma Nacional de Transparência do México. Adicionalmente, a tecnologia pode ser viabilizadora do fortalecimento de direitos: como com o uso de identidades encriptadas, por exemplo (Schulz \& Hoboken, 2016). Dessa forma, garante-se o respeito à vedação ao anonimato, ao mesmo tempo em que se previne a discriminação ou retaliação por perguntas enviadas aos entes públicos.

A garantia da neutralidade da identidade faz-se vital para o pleno exercício do direito de informar-se. Para isso, é necessário que se reduza a discricionariedade com que os órgãos públicos estabelecem seus requisitos de identificação, entregando o ônus da proteção das informações pessoais de identidade aos Estados, caso não aceitem pedidos anônimos. Permanece, no entanto, a seguinte dúvida: se apenas informações essencialmente públicas são fornecidas, de onde nasce a necessidade de identificação?

\section{Referências Bibliográficas}

Abdala, P. R. Z., \& Torres, C. M. S. de O. (2016). A Transparência como Espetáculo: uma análise dos portais de transparência de estados brasileiros. Administração Pública e Gestão Social, 8(3), 147-158. https://doi.org/10.21118/apgs.v1i3.1023

ACHPR. (2013). Model Law on Access to Information for Africa. Retrieved from http://www.achpr.org/instruments/access-information

Alves, M. S. D. (2011). Do sigilo ao acesso: análise tópica da mudança de cultura. Revista Do Tribunal de Contas Do Estado de Minas Gerais (Transparência e Controle Social), 120-134.

Article 19. (1999). The public's right to know: Principles on Freedom of Information legislation. . . International Standards Series. https://doi.org/10.1038/275682a0

Article 19. (2006). A Model Freedom of Information Law. Article 19. Retrieved from http://www.article19.org/resources.php/resource/1796/en/

Barros, M., \& Rodrigues, K. F. (2017). Transparência em Compras Públicas no âmbito local no Brasill. In M. F. Mohallem \& C. E. J. Ragazzo (Eds.), Diagnóstico institucional: primeiros passos para um plano nacional. Rio de Janeiro: FGV Direito Rio.

Bertoni, E. A. (2011). Libertad de información. ¿Tres palabras inofensivas? Leyes de acceso a la información y rol de la prensa. Washington. Retrieved from

LibertaddelnformacionyPrensa.pdf

Centro de Archivos y Acceso a la Información Pública. (2011). Venciendo la Cultura del Secreto. Montevideo: Centro de Archivos y Acceso a la Información Pública.

Council of Europe. Council of Europe Convention on Access to Official Documents, Pub. L. No. 205 (2009).

Cruz, C. F., Ferreira, A. C. D. S., Silva, L. M. Da, \& Macedo, M. Á. D. S. (2012) Transparência da gestão pública municipal: um estudo a partir dos portais eletrônicos dos maiores municípios brasileiros. Revista de Administração Pública, 46(1), 153-176. https://doi.org/10.1590/S0034-76122012000100008 Cuillier, D. (2010). Honey v. vinegar: Testing compliance-gaining theories in the context of freedom of information laws. Communication Law and Policy, 15(3), 203-229. https://doi.org/10.1080/10811680.2010.489842

Divorski, S., Gordon, A. C., \& Heinz, J. P. (1973). Public access to government information: A field experiment. Nw. UL Rev, 68, 240.

Doneda, D. (2011). A proteção dos dados pessoais como um direito fundamental. Espaço Jurídico, 12(2), 91-108.

Dowbor, L. (2003). Informação para a cidadania e o desenvolvimento sustentável. Lua Nova: Revista de Cultura e Política, 58.

European Parliament \& Council. Regulation (EC) No 1049/2001 of The European Parliament and of the Council of 30 May 2001 regarding public access to European Parliament, Council and Commission documents, Brussels Official Journal /L 145/43, § (2001). Bruxelas.

Fundación Pro Acceso, Corporación Participa, Fundación Pro Bono Fundación Ciudadano Inteligente, Escuela de Periodismo de la Universidad Diego Portales, \& Ciudad Viva. (2010). Obstáculos a la información pública: una revisión de casos ciudadanos. Santiago: Fundación Pro Acceso Corporación Participa, Fundación Pro Bono, Fundación Ciudadano Inteligente, Escuela de Periodismo de la Universidad Diego Portales, Ciudad Viva.

G1. (2016, July 19). WhatsApp: Justiça do RJ manda bloquear aplicativo em todo o Brasil. G1. Rio de Janeiro. Retrieved from http://g1.globo.com/tecnologia/noticia/2016/07/whatsapp-deve-serbloqueado-decide-justica-do-rio.html

Grohs, S., Adam, C., \& Knill, C. (2016). Are Some Citizens More Equal than Others? Evidence from a Field Experiment. Public Administration Review, 76(1), 155-164. https://doi.org/10.1111/puar.12439

Gruman, M. (2012). Lei de Acesso à Informação: notas e um breve exemplo. Revista Debates, 6(3), 97. https://doi.org/1982-5269

Hott, D. F. M. (2005). O Acesso aos Documentos Sigilosos: um estudo das comissões permanentes de avaliação e de acesso nos arquivos brasileiros. Universidade de Brasília.

INAI. (2017). Plataforma Nacional de Transparencia. Retrieved from

\footnotetext{
2 Uma versão deste artigo foi enviada à CGU, resultando na recente inclusão da proteção da identidade do requerente no portal brasileiro da Lei de Acesso à Informação. Veja mais em
}

https://exame.abril.com.br/brasil/governo-vai-proteger-identidade-de-quempede-informacao-publica/. 
http://www.plataformadetransparencia.org.mx/web/guest/inicio

Lagunes, P. (2009). Irregular transparency? An experiment involving Mexico's freedom of information law. Social Science Research Network, (May), 1-29. Retrieved from https://ssrn.com/abstract=2270265

Lagunes, P., \& Pocasangre, O. (2016). Dynamic Transparency: An Audit of Mexico's Freedom of Information Act (CDEP-CGEG Working Paper Series No. 28). Retrieved from http://cdep.sipa.columbia.edu/sites/default/files/cdep/WP 28 Lagunes.pdf

Leach, W. D. (2006). Collaborative Evidence and Democracy: Collaborative Public Management from Western Watershed Partnerships. Public Administration Review, 66(Special Issue: Collaborative Public Management), 100-110. https://doi.org/10.1111/j.1540-6210.2006.00670.x

Lopes, C. A. (2011). O uso das Tecnologias da Informação e Comunicações nas políticas de acesso à informação pública na América Latina. In I Circuito de Debates Acadêmicos. Brasília: IPEA. Retrieved from http://www.ipea.gov.br/code2011/chamada2011/pdf/area9/area9-artigo5.pdf

Marquez, F. (2017, October 25). Brasil é o sétimo país do mundo em número de jornalistas assassinados. Folha de São Paulo, pp. 7-9. São Paulo. Retrieved from https://www1.folha.uol.com.br/mundo/2017/10/1930121brasil-e-o-setimo-pais-do-mundo-em-numero-de-jornalistasassassinados.shtml

Martin, J. A., \& Fargo, A. L. (2015). Anonymity As a Legal Right: Where and Why It Matters. North Carolina Journal of Law and Technology, 16(2), 311376.

McDonagh, M., \& Paterson, M. (2010). Freedom of Information: Taking Account of the Circumstances of Individual Applicants. Public Law, 505-529. Retrieved from http://www.academia.edu/download/30464719/2010_PL_Issue_3_McDonag h.pdf

Mendel, T. (2008). Freedom of Information: a comparative legal survey $\left(2^{\mathrm{a}}\right)$. Paris: Unesco. Retrieved from http://www.foia.it/docs/foia-it_doc006.pdf

Michener, R. G. (2010). The Surrender of Secrecy: Explaining the Emergence of Strong Access to Information Laws in Latin America. University of Texas at Austin.

Michener, R. G. (2011). FOI Laws Around the World. Journal of Democracy, 22(2), 145-159. https://doi.org/10.1353/jod.2011.0021

Michener, R. G., Moncau, L. F. M., \& Velasco, R. B. (2014). Avaliação Geral. (R. G. Michener, L. F. M. Moncau, \& R. Velasco, Eds.), Estado Brasileiro Transparência: avaliando a aplicação da Lei de Acesso à Informação. Rio de Janeiro: FGV.

Michener, R. G., \& Rodrigues, K. (2015). "Who Wants to Know?" Assessing Discrimination in Transparency and Freedom of Information Regimes. 4rd Global Conference Os Transparency Research, 1-19.
Michener, R. G., \& Rodrigues, K. F. (2017, November 10). Salvando a transparência subnacional. Estadão. São Paulo. Retrieved from http://saopaulo.estadao.com.br/noticias/geral,salvando-a-transparencia-

subnacional,70002079970

Moncau, L. F. M., Michener, R. G., Barros, M., \& Velasco, R. B. (2015) Avaliação de Transparência do Ministério Público. Rio de Janeiro: Fundação Getúlio Vargas.

Nogami, T., \& Yoshida, F. (2013). The pursuit of self-interest and rule breaking in an anonymous situation. Journal of Applied Social Psychology, 909-916. https://doi.org/10.1111/jasp.12056

OEA. (2010). Model Inter-American Law on Access to Public Information.

Open Society Justice Initiative. (2006). Transparency \& Silence: a survey of access to information laws and practices in 14 countries. New York: OSF. Retrieved from https://www.opensocietyfoundations.org/sites/default/files/transparency_200 60928.pdf

OpenGovData. (2007). 8 Principles of Open Government Data. Retrieved from https://public.resource.org/8_principles.html

Peisakhin, L. (2012). Transparency and Corruption: Evidence from India. The Journal of Law and Economics, 55(1), 129-149.

Rains, S. A., \& Scott, C. R. (2007). To Identify or Not to Identify: A Theoretical Model of Receiver Responses to Anonymous Communication. Comunication Theory, 17, 61-91. https://doi.org/10.1111/j.1468-2885.2007.00288.x

Rajam, K. (2017, September 28). 65 RTI activists murdered since 2005 here's a tribute to India's fallen heroes. Yourstory, pp. 1-9. Retrieved from https://yourstory.com/2017/09/rti-activists-murdered/

Roberts, A. (2006). Blacked out: Government Secrecy in the Information Age. Cambridge: Cambridge University Press.

Rodrigues, K. F. (2017). Democratic Transparency Pacts on Defense: Assessing change in civilian access to military information in Brazil. FGV.

RTI Rating. (2017). Global Right to Information Rating. Retrieved from http://www.rti-rating.org/

Schommer, P. C., Dahmer, J., \& Spaniol, E. L. (2014). Controle Social no Brasil - Estadocêntrico ou Sociocêntrico? Evidências da $1^{\text {a }}$ Conferência Nacional sobre Transparência e Controle Social, Consocial. Administração Pública e Gestão Social, 6(1), 1-55.

Schulz, W., \& Hoboken, J. van. (2016). Human rights and encryption (UNESCO Series on Internet Freedom Human rights and encryption).

Souza, C. (2006). Políticas Públicas: uma revisão da literatura. Sociologias, 8(2003), 20-45. https://doi.org/10.1590/S1517-45222006000200003

Velasco, R. B. (2017). Who Wants to Know? A Field experiment to Assess Discrimination in Freedom of Information Regimes. Fundação Getúlio Vagas. 